\title{
LOCAL ANESTHETICS AND STEROIDS: CONTRAINDICATIONS AND COMPLICATIONS - CLINICAL UPDATE
}

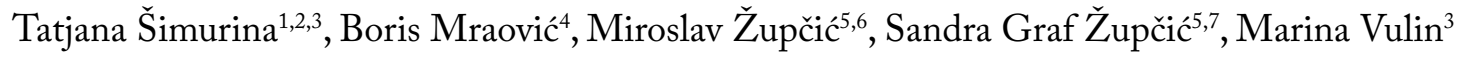 \\ ${ }^{1}$ Department of Anesthesiology, Resustitation, Intensive Medicine and Pain Management, Faculty of Medicine, \\ "Josip JurajStrossmayer" University, Osijek, Croatia; ${ }^{2}$ Department of Health Studies, University of Zadar, \\ Zadar, Croatia; ${ }^{3}$ Department of Anesthesiology, Reanimatology and Intensive Care Medicine, \\ Zadar General Hospital, Zadar, Croatia; ${ }^{4}$ Department of Anesthesiology and Perioperative Medicine, \\ School of Medicine, University of Missouri, Columbia, USA; ${ }^{5}$ School of Medicine, University of Rijeka, \\ Rijeka, Croatia; ${ }^{6} \mathrm{Clinic}$ of Anesthesiology and Intensive Care Medicine, Clinical Hospital Centre Rijeka, \\ Rijeka, Croatia; ${ }^{7}$ Clinic of Neurology, Clinical Hospital Centre Rijeka, Rijeka, Croatia
}

SUMMARY - The objective of this clinical update, based on recently published literature, was to discuss incidence and characteristics of the most relevant clinical adverse effects associated with local anesthetic and steroid use in regional anesthesia and treatment of acute or chronic pain. A comprehensive review of the English-language medical literature search utilizing PubMed, Ovid Medline ${ }^{\circledR}$ and Google Scholar from 2015 to 2018 was performed. This narrative review provides anesthesia practitioners with updated evidences on complications and contraindications of local anesthetic and steroid use with emphasis on current points of view regarding prevention, early diagnosis and treatment of adverse events.

Keywords: Anesthetics, Local; Anesthetics, Local/adverse effects; Anesthetics, Localltoxicity; Anesthetics, Local/complications; Steroids/adverse effects; Steroids/complications; Regional anesthesia and analgesia.

\section{Introduction}

Local anesthetics (LAs) are generally safe and widely used medications and have been used in various clinical settings for decades. There are different routes of administration such as intravenous, topical, subcutaneous and tissue infiltration, peripheral nerve blocks, epidural, spinal, caudal or intraarticular. The introduction of new regional anesthetic techniques, emergence of new LAs, novel approaches in administration such as high-volume tissue plane blocks and local infiltration analgesia (LIA) contribute to the increasing use of local anesthetic. Local anesthetics and corticosteroids are frequently used in combination, mostly for diagnosis and treatment of musculoskeletal

Correspondence to: Tatjana Šimurina, $M D, P h D$, General Hospital, Bože Peričića 5, 23000 Zadar, Croatia

E-mail:tsimurina@unizd.hr, tatjana.simurina@mefos.hr disturbances. Corticosteroids are mainly used because of their anti-inflammatory properties. Common routes of corticosteroid administration are intraarticular, epidural, transforaminal as well as bursal or tendon sheath injections.

Increased use of LAs and steroids may increase incidence of major adverse effects and complications. Although they are rare, anesthesia practitioners must be aware of potential catastrophic events. Complications of steroid injections can vary in severity from minor - such as skin depigmentation - to major - such as joint empyema. Also, LAs may cause complications in a broad spectrum of clinical manifestations from minor signs and symptoms to local anesthetic systemic toxicity (LAST) that can result in disability or even death. With an implementation of new regional anesthesia techniques and adherence to dosage recommendations and new guidelines for the management of 
complications, the incidence of severe LA complications should decrease ${ }^{1}$.

The objective of this narrative review was to summarize current knowledge concerning complications and contraindications of LAs and steroids, update on incidence, early recognition of signs and symptoms of adverse events, prevention and therapy of complications with practical recommendations.

\section{Methods}

We have searched medical literature published on English on PubMed, Ovid Medline ${ }^{\circledR}$ and Google Scholar search. We included peer-reviewed professional articles, review articles, retrospective and prospective studies, case reports, case series published from January 2015 to December 2018, but excluded editorials and letters to editors, animal experiments, in vitro studies, studies in infants and children and data available only in abstracts. The search strategy consisted of the following Medical Subject Headings (MeSH) terms: Anesthetics, Local; Anesthetics, Local/adverse effects; Anesthetics, Local/toxicity; Anesthetics, Lo$\mathrm{cal} /$ complications. The initial screen was based on titles and abstracts of articles on LA adverse effects and complications. First, we have read the abstracts of 130 papers and excluded 90 irrelevant articles. We have read 40 full-text articles and excluded articles which do not meet inclusion criteria and not mentioning regional anesthesia and pain management. Limitations to retrieval of data from case reports include selection and reporting bias. Extraction of data from administrative database and surrogate markers may overestimate the incidence of LA adverse events when compared to clinical registries. In addition, we repeated the same search with the same inclusion and exclusion criteria in the same databases using $\mathrm{MeSH}$ keywords: Steroids/adverse effects; Steroids/complications; Regional anesthesia and analgesia. First, we have read the abstracts of 74 papers and excluded irrelevant articles. We have then read 24 full-text articles and excluded articles which do not meet inclusion criteria or not mentioning regional anesthesia and pain management.

\section{Results}

Out of 130 articles, 40 articles were identified and twenty seven articles (seventeen review articles, special articles, retrospective analysis and ten case reports) with relevant information on LA complications (adverse events) were selected. We excluded two articles for continuing education and one review of LA effects in cutaneous surgery. A critical appraisal was performed based on the twenty four selected studies and summarized updated information on LAs complications and contraindications.

Out of 74 articles on steroid adverse effects and complications, 24 articles were identified. We extracted eight most important articles (5 review articles, 2 case reports and 1 retrospective analysis) to summarize updated information on steroid complications and contraindications.

\section{Discussion}

\section{Local anesthetic complications and contraindications}

The present knowledge on adverse effects and complications following administration of LAs in humans are derived from animal and in vitro studies, case reports, case series, clinical registries, observational and epidemiologic studies. Ethical concerns preclude randomized controlled trials (RCTs) because patients suffering adverse events cannot be recruited to RCT. We retrieved relevant information on local anesthetic complications published during the last five years in order to update the current knowledge on this topic.

\section{Epidemiology of local anesthetic complications}

The incidence of LAST is around three per 10,000 peripheral nerve blocks (PNBs) ${ }^{2}$. PNBs require larger doses of LA than neuraxial blocks, significantly increasing the risk for LAST.In most recently published reports, rates of serious cases of LA toxicity (seizures with or without cardiac collapse) are 1:10,000 for epidural analgesia but ten times higher for $\operatorname{PNBs}(1: 1000)^{3}$. Liu et al. ${ }^{4}$ identified three LAST cases from 80,661 patients who received $\mathrm{PNBs}$ and found no cases of cardiac arrest $\mathrm{PNBs}(0 / 1000 \mathrm{PNBs}, 95 \%$ confidence interval $[\mathrm{CI}] 0-0.05 / 1000)$ and 3 cases of seizures (0.04/1000 PNBs, 95\% CI 0.01- 0.11/1000). Mörwald EE, et al. ${ }^{5}$ searched a large nationally representative administrative database and determined cumulative rate of patients' outcomes (cardiac arrest, seizures, and use of intralipid on the day of surgery) of $0.18 \%$ in $238,473(1.8 / 1000)$ orthopedic patients for total joint 
arthroplasties who received PNBs. In this recent retrospective cohort study, the incidence of LAST was low but clinically meaningful and decreased significantly during the study period. Rubin DS et al. ${ }^{6}$ also searched a large national database from 1998 to 2013 with 710,000 patients who had adjunct PNBs placed for total joint arthroplasty of the hip, knee and shoulder, revealed an average adjusted incidence of 1.04 (95\% CI 0.49-1.80) LAST events per 1000 PNBs with decreasing trend over the study period. Major LAST complications were present in 0.22 per 1000 PNBs. Gitman $\mathrm{M}$ and Barrington $\mathrm{MJ}^{7}$ determined the incidence of LAST $0.03 \%$ or 0.27 (95\% CI, 0.21-0.35) per 1000 PNBs (denominator of 251.325) from online registries with data on ILE therapy. They have been established that seizure was the most common adverse event (53\% from recently published case reports and $61 \%$ from online registries).

The incidence of LAST is likely underreported because of misdiagnosis, especially in practitioners other than anesthetists, lower reporting of minor events, atypical and unusual clinical manifestation, delayed onset of symptoms as well as publication bias. New regional anesthesia techniques reduce the incidence of LAST but persistent vigilance is crucial for the prevention and treatment of this life-threatening complications.

\section{Risk factors, clinical manifestations, prevention and treatment of $L A$ complications}

Adverse reactions may occur because of dosing error or rapid absorption of injected LAs in highly vascular tissues. LA toxicity is most often caused by inappropriate LA administration such as accidental intravascular injection or multiple injections. Toxic events can occur very fast following intravascular injection or can be delayed when absorbed from local tissue injection $^{8}$. Maximal safety dose of LA should not exceed the recommended dose because morbidity and mortality from LA significantly increases in higher doses. Adverse events of LA may be systemic or local. Signs and symptoms of systemic toxicity depend on affected organ systems. High doses of LAs cause initial clinical manifestations of CNS stimulation including circumoral and tongue numbness, metallic taste, visual and auditory disturbance (eyes-focusing difficulty and tinnitus), lightheadedness, drowsiness, confusion, disorientation and dizziness. CNS symptoms may progress to CNS depression with muscle twitching and convulsions, onset of unconsciousness and coma with respiratory arrest. Cardiovascular symptoms may be preceded by CNS symptoms. Cardiovascular (CV) manifestations include chest pain, shortness of breath, bradycardia, dysrhythmias, hypotension, syncope, myocardial depression and cardiac collapse. Patients with preexisting cardiac conduction abnormalities or heart failure are at particular risk.

CNS symptoms are more often associated with lidocaine use rather than bupivacaine. Nicholas $\mathrm{E}$ et al. ${ }^{9}$ reported a case of a young man with persistent epistaxis. He developed severe lidocaine toxicity resulting from a topical anesthesia with $2 \%$ lidocaine prior to intranasal cautery. Intranasal LA has a variable absorption and dosing could be difficult. Signs of lidocaine toxicity included sleepiness, generalized shaking episode, nausea, vomiting, bradycardia, and hypotension, but it was recognized immediately and successfully treated with lipid emulsion.

Risk of cardiovascular toxicity is greater with lipophilic LA like bupivacaine. Nelson $\mathrm{M}$ et al. ${ }^{10}$ presented a case of a 66-year-old man with diabetes, hypothyroidism, sleep apnea, surgical history of coronary artery bypass grafting and lobectomy from lung cancer, who developed profound and prolonged bradycardia, and hypotension immediately after interscalene brachial plexus block with $0.5 \%$ bupivacaine for elective rotator cuff surgery.

Hematologic reactions include methemoglobinemia which is associated with use of benzocaine, prilocaine and lidocaine. They are metabolized by the liver to ortho-toluidine that converts hemoglobin to methemoglobin. High levels of methemoglobulin lead to cyanosis, tachypnea, fatigue, weakness, dizziness and syncope. In the case of severe reaction, methylene blue and hyperbaric oxygen are the treatment options.

Commonly patients and even medical personnel misinterpret and record adverse reactions as an allergy to LA. But more likely they are reactions to adjuvants, like epinephrine, vasovagal syncope or overdose toxicity. Allergy occurs very rarely and includes rash, urticaria and anaphylaxis. Hydrolysis of amino esters by cholinesterase results in the release of para-aminobenzoic acid which is the main cause of LA acute allergic reactions. Amide-type LAs are metabolized in the liver and true allergy to amide LAs is very rare. Allergic reactions to amide LAs are mostly attributed to 
additives which are well-known allergens such as metabisulfite or methylparaben. A recent case report by Bina $\mathrm{B}$ et al. ${ }^{11}$ reported a middle-aged woman with documented history of anaphylactic reaction to lidocaine. True allergy to LA is a contraindication for use of other anesthetics from the same chemical classes (esters or amides). But her allergist declined to test her for ester-type allergies because of previous anaphylactic reactions to amide type LA during testing. The patient wanted to avoid general anesthesia and dental treatment was performed under maxillary infiltration with anesthetic mixture of $1 \%$ diphenhydramine with 1:100.000 epinephrine. This emphasizes that patients should be informed of alternative medications and forms of treatment.

Symptoms of LA sensitivity may be atypical. Hayaran $\mathrm{N}$ et al. ${ }^{12}$ presented an unusual case of a young man who underwent dental surgery and his lower lip mucosa and vestibule was infiltrated with $2 \%$ lignocaine with adrenaline. The patient had a skin sensitivity test negative before the surgery. The patient became unconscious 20 minutes after injection, actually at the end of the surgery. He was unconscious for six hours but there was no seizure activity. The blood level of LA was inside safety range. An electroencephalogram (EEG) showed posterior cortical dysfunction and global cerebral depression. After a repeated dose of lipid emulsion he regained full consciousness. Detailed medical history and discussion with the family revealed that he had already experienced similar loss of consciousness for 2 hours after previous dental intervention under local anesthesia. All health-care practitioners should pay attention to atypical and delayed manifestations of LA reactions.

Local tissue manifestations of LA toxicity are numbness, paresthesia, irreversible conduction block, peripheral neurotoxicity (prolonged sensory and motor deficits) and reversible skeletal muscle damage ${ }^{13}$. Some authors reported rare and unexpected LA complications. Neal JM et al. ${ }^{14}$ documented three cases of LA-induced myotoxicity after continuous adductor canal block for pain management after total knee arthroplasty. The patients developed progressive, profound non-neurogenic weakness of the quadriceps muscle. This finding was contrary to previously accepted opinion that LA-myotoxicity is a subclinical disturbance in humans.Myotoxicity risk factors include higher concentrations, prolonged exposure to LA and use of bupivacaine ${ }^{15}$.
Local sepsis and coagulopathy are relative contraindications to musculoskeletal injections because of the higher risk for septic complications or hemorrhage. It is known that infusion of $0.5 \%$ bupivacaine with epinephrine through an intra-articular pain pump catheter may increase the risk for joint chondrolysis ${ }^{16}$.

Risk factors for local anesthetic adverse effects are: individual risk factors, comorbidities (higher pulmonary, cardiac and nervous susceptibilities), taking medications, site of LA administration (injection into a vessel-rich tissue), technique of block applied, bolus injection without aspiration test, specific local anesthetic compound, large total local anesthetic dose, timeliness of diagnosis, and treatment with adherence to the practice advisory ${ }^{17,18}$.

A case report by Tierney KJ et al. ${ }^{19}$ showed that overdoses of LAs can lead to fatal complications. Three times the maximum recommended dose of lidocaine was used for local infiltration in a middle-aged woman during the incision of a labial abscess. Her medical history revealed that she had multiple comorbidities and was taking atrioventricular nodal blocking agents. After the surgery, she vomited and had altered mental status with seizure requiring endotracheal intubation. Cardiac arrest followed cardiovascular collapse with pulseless electrical activity (PEA). The rapid ILE was applied and return of spontaneous circulation occurred. She was discharged with no neurological sequels. Early recognition of adverse events is critical but prevention is the most important. Use of appropriate and individualized doses can prevent catastrophic outcomes.

Individual risk factors include age, weight, comorbidities, taking medications, genetic factors, allergies, renal and hepatic dysfunction, and cardiac disease. Older patients and those with lower skeletal muscle mass, which could serve as storage for excess of LA, have increased risk for LAST. Elderly patients have reduced clearance of LA due to physiologically decreased systemic blood flow and liver function leading to increased potential for drug accumulation. LA dose reduction is not necessary in patients with renal dysfunction except in patients with uremia and metabolic acidosis. Despite a higher total plasma LA concentration in patients with renal dysfunction, the free plasma concentration remains unchanged because of the increase in $\alpha_{1}$ acid glycoprotein concentration. Ropiva- 
caine and levobupivacaine are favorable in patients with cardiac disease because of their low cardiotoxic potential. However, dose reduction of LA is recommended in advanced heart failure because of increased risk for myocardial depression and arrhythmias. Hepatic dysfunction is associated with reduced clearance of LAs and higher volume of distribution. Dose adjustment of LAs should be taken into consideration in advance hepatic dysfunction. Moreover, Lee JE et al. ${ }^{20}$ described an acute liver injury in an older man with history of liver transplantation who received regular immunosuppressive therapy. The patient underwent bilateral total knee arthroplasty under general anesthesia and bupivacaine was injected into each knee for postoperative analgesia. Liver enzyme levels increased enormously and remained extremely high during the first postoperative day. Clinical exam and laboratory findings suggested bupivacaine-induced liver injury. Anesthesia providers should be aware that local anesthetics may disrupt the graft function.

Ropivacaine has a duration of action similar to bupivacaine but it has lower potential for cardiotoxicity. It is metabolized in the liver by liver enzymes. Recently, Tsang TM et al. ${ }^{21}$ demonstrated delayed LAST in a 66 year old man who underwent thoracotomy for pleural biopsies of tumor with continuous paravertebral block for analgesia with ropivacaine. Thirty-seven hours after the test dose of LA, the patient developed LAST symptoms: perioral tingling, burning sensation in legs and penis, agitation, convulsions affecting the limbs but no unconsciousness. LAST symptoms were resolved soon after stopping LA infusion and administering intravenous lipid emulsion. Contributing factors to LAST may be the proximity of the catheter to vascular area of tumor and pleural biopsy site, as well as, a concomitant prescription of amitriptyline (tricyclic antidepressant) which can produce inhibition of liver enzymes that metabolize ropivacaine. It is well known that ropivacaine may cause vasoconstriction of arterioles supplying the CNS and should not be used in transforaminal injections because of the risk of CNS infarction.

The site of the injection influences the absorption of LA with lowest to highest absorption rate as follows: subcutaneous tissue, brachial plexus, epidural, caudal and intercostal spaces. A recent review of case reports and registries by Gitman $\mathrm{M}$ et al. ${ }^{7}$ showed that local infiltration analgesia (LIA) in adult patients was associated most commonly (17\%) with LAST events followed by neuroaxial block (13\%), lower/upper extremity block (8.5\%), head/neck block (8.5\%) and paravertebral blocks (8.5\%). These results are influenced by total doses of LAs and vascularity of the injected site. As could be expected, bupivacaine was involved more often in LAST cases (36\%) than lidocaine (26\%) and ropivacaine (21\%). CNS symptoms were the most frequent $(77 \%, 36 / 47)$ with seizure as the most common feature $(53 \%, 25 / 47)$. The highest incidence of LAST (39\%) was in patients aged from 20 to 70 years.

An increased risk for LAST after PNBs was seen in shoulder arthroplasty compared with knee and hip arthroplasty. Further, risk factors associated with LAST are large and medium size hospitals as compared with small hospitals ${ }^{6}$. The incidence of systemic toxicity after regional block is $1: 1000$ for nerve stimulator guided block and 1:1600 for ultrasound-guided regional anesthesia (UGRA). The use of ultrasound guidance allows for precise visualization of the needle, nerves and blood vessels. This allows the use of smaller LA volumes and fewer side effects. Also, more common in UGRA is an administration of smaller volumes in two or more sites around the nerves which reduces the risk of injection of the full volume of LA intravascularly. In nerve stimulator technique full volume is usually given in the same site. UGRA reduces intravascular injection of LA but may not be widely available in smaller hospitals when compared to large health-care centers. Emerging evidence in a review of recent literature by Neal JM ${ }^{22}$ supports the effectiveness of ultrasound guided techniques for reducing LAST by $65 \%$ across its clinical presentation from minor to major symptoms. But LAST still occurs and continues to be reported as sporadic case reports.

In a review of LAST case reports, Vasques $\mathrm{F}$ et al. ${ }^{23}$ confirmed that comorbidities have an important role in predisposing patients to LAST, but $27 \%$ of LAST events developed in otherwise healthy patients. CNS toxicity occurred in 50\% of all reported LAST cases, mixed CNS and CV toxicity were reported in 36\% of the cases and $14 \%$ cases presented CV toxicity. Lateonset LAST (longer than 10 minutes) was more frequent (45\%) than rapid onset (less than 1 minute, $18 \%)$. This shows that LAST is an unpredictable phenomenon with atypical manifestations from time to 
time and mandates for vigilance to detect prodromes. The most frequent LAST events occurred in operative room $(69 \%)$ and were associated with interscalene block (23\%) followed by epidural/caudal block (16\%). Authors concluded that ILE therapy may be under administered in current clinical practice.

Protein binding of LAs is decreased during pregnancy causing higher sensitivity to LAs. Functional changes during pregnancy with influence of hormones on cardiac myocytes, increased neuronal sensitivity to LAs and engorged epidural veins contribute to higher risk for LAST. LAST in an expectant mother who received bupivacaine in combined spinal-epidural analgesia for labor started fifty minutes from the first LA administration ${ }^{24}$. She felt metallic taste, tinnitus and palpitations. Epidural infusion was stopped immediately and symptoms were resolved within 10 minutes of $20 \%$ intralipid administration.

Park H-S et al. ${ }^{8}$ showed that interscalene brachial plexus block (ISB) is contraindicated in patients with preexisting contralateral vocal cord palsy or paresis. Recurrent laryngeal nerve block is rare, but it is a possible complication of continuous ISB for shoulder surgery which may lead to acute respiratory failure in patients with contralateral vocal cord palsy. Authors recommend detailed medical history, examination of the upper airway, ultrasound guided injections of LAs and lower concentrations of LAs.

Healthcare providers who administered LAs must be familiar with guidelines on the management of LAST $^{7}$. Neal JM et al., ${ }^{25}$ showed that non-use of American Society of Regional Anesthesia and Pain Medicine (ASRA) checklist as a reminder of therapeutic interventions worsens therapeutic performance during LAs adverse events. Updated ASRA practice advisory guidelines ${ }^{26}$ from 2017, recommend airway protection first and then start of ILE because hypoxia, hypercapnia and acidosis can promote LAST. ILE therapy is simplified and easy to memorize. Initial bolus of $100 \mathrm{~mL}$ lipid emulsion was followed by the infusion rate of 200 to $250 \mathrm{~mL}$ over 15 to 20 minutes for patients weighing more than $70 \mathrm{~kg}$. Benzodiazepines are the first choice for seizure treatment but small boluses of propofol may be used. Special considerations in cardiac arrest treatment include reduced doses of epinephrine $(\leq 1 \mathrm{mcg} / \mathrm{kg})$ but medications such as vasopressin, beta and calcium channel blockers and local anesthetics (lidocaine and IB antiar- rhythmics) are contraindicated. If ventricular arrhythmias develop, amiodarone is preferable. If ILE and vasopressor therapy failed, cardiac pacing and cardiopulmonary bypass may improve the outcome. Monitoring of vital signs lasts for 4 to 6 hours after cardiovascular adverse event and at least 2 hours after CNS adverse events ${ }^{13,26}$.

The prevention of adverse events should be the primary goal. Many complications could be avoided by adherence to the recommended LA doses using the lowest effective doses, as well as appropriate administration technique with incremental injection and testing doses. Maintaining verbal contact with the patient during the entire procedure serves as a close monitoring. Patients' cooperation is also important. They can be informed with additional educational materials and online resources (lipidrescue.org).

Recently published case reports suggest a trend toward atypical and delayed clinical manifestations. The major causes may be in more precise nerve localization with ultrasound guidance of the needle and consequently lower incidence of intravascular injection and local infiltration techniques with slower uptake into systemic circulation. However, there is a need for continued education of health-care providers, including anesthetists, surgeons, dentists, emergency medicine physicians and others who are involved in LA administration about prevention, recognition and treatment of acute and chronic adverse effects.

\section{Steroids}

Corticosteroids are routinely injected into soft tissues, tendon sheaths, bursae and joints. Corticosteroids are esters or non-esters. Corticosteroid esters (e.g. methylprednisolone acetate, triamcinolone acetonide, betamethasone acetate) are insoluble in water and form microcrystalline suspensions. They are hydrolyzed by cellular esterases to release the active compounds. As a result, they have longer half-lives and prolonged activity in the joints when compared with non-esters. Corticosteroid non-esters (e.g. dexamethasone and betamethasone) are freely soluble in water and preparations are clear (non-particulate). Non-esters are taken by cells rapidly and have a faster onset of activity but shorter duration of action when compared with esters ${ }^{27}$. 


\section{Epidemiology, clinical manifestations, prevention and treatment of steroid complications}

Adverse effects of corticosteroids are rare, but when they occur, the consequences could be serious. Aseptic technique should be strictly applied to keep the incidence of septic arthritis as low as $0.01-0.03 \%$. A septic joint is associated with significant morbidity and mortality of $11.5 \%$. Post injection "flare" mostly caused by microcrystalline steroid esters is the most common adverse effect with prevalence of 2-25\%. In case of a local increase of inflammation longer than 24 hours, a joint infection must be excluded by aspiration. "Flare" develops within hours following injection and lasts 2-3 days. Extraarticular injections may be associated with local tissue necrosis, calcification, as well as tendon rupture that could be caused by inhibition of tenocyte proliferation. These complications could be minimized by injection with caution from an experienced practitioner. Soft tissue injections may cause skin depigmentation, fat necrosis, as well as, cutaneous atrophy which may be effectively treated by local infiltration of normal saline ${ }^{27}$.

Multiple injections into the joint increase the risk of articular cartilage loss and the incidence is $0.7-3 \%$. Steroid toxicity is related to both the average dose and cumulative duration of use. Corticosteroids have a time dependent and dose dependent deleterious effects on articular cartilage and minimal effective doses should be used. Doses should be estimated according to the size of injected joint and the frequencies of injections should be limited ${ }^{28}$.

Systemic effects of steroid soft tissue or intraarticular injections have small clinical significance. Patients should be advised to avoid surgery and risk of trauma or infections within two weeks after steroid injections because of increased risk of adrenal crisis. Diabetic patients should be warned to expect hyperglycemia for 2 to 5 days following steroid injections. Facial flushing accompanied with coldness, shaking and headaches may occur secondary to histamine release and symptoms can be reduced with antihistamines and choice of another steroid ${ }^{29}$.

In a recent systemic review and meta-analysis of eight randomized controlled trials (RCTs) including 771 patients of which 366 patients received epidural steroids (particulate and nonparticulate), Bhatia A et al. ${ }^{30}$ reported sporadic occurrence of adverse effects in only two RCTs such as hyperglycemia, myopathy and neurologic injuries. It is important for the anesthetists, radiologists, orthopedic surgeons and pain physicians to be aware that a rare adverse event may suddenly occur after steroid injection. A recent case report described segmental spinal myoclonus during lumbar transforaminal epidural injection with particulate steroid triamcinolone ${ }^{31}$. Adverse central nervous system events such as brain and spinal cord infarction and paraplegia are caused by vascular injuries, embolic infarction after particulate steroid intraarterial administration and neurotoxicity from preservatives and drug vehicles. New challenges arise when practitioners perform interventional procedures on patients who are anticoagulated. Even with adherence to guidelines for performing neuroaxial injections in the setting of anticoagulants, patients may develop an epidural hematoma and paraplegia after thoracic epidural steroid injection $^{32}$. Combination of LAs and steroids improves postoperative analgesia. A recent meta-analysis of fourteen studies with a total of 1,022 patients showed that lower doses of 4-5 $\mathrm{mg}$ perineural dexamethasone added to LA for brachial plexus block improves postoperative analgesia without increasing the incidence of complications including nausea, hoarseness, dyspnea and Horner's syndrome ${ }^{33}$.

Contraindications to the use of corticosteroid injections may be absolute or relative. Absolute contraindications are local infection, sepsis and bacteremia to avoid spreading of infection. Steroids inhibit bone healing and should be avoided in the case of intraarticular fracture. Steroids are contraindicated in joint instability because of the risk of subchondral osteonecrosis and weakening of the joint structures. Relative contraindications are: juxta-articular osteoporosis because of the fear for further decrease of bone density, coagulopathy, injection three times per year or within six weeks ${ }^{29}$. There is an increased risk of intraoperative and postoperative joint infection if total hip arthroplasty is performed within 3 months of hip steroid injection. New recommendations consider delaying elective total hip arthroplasty for 3 months after an injection to avoid this elevated risk of infection ${ }^{34}$.

According to the recent literature, adverse events associated with steroid injections in soft tissue and joints in regional analgesia and pain management are rarely reported. The indication for pain treatment 
should be justified and patients informed of the benefits, risk of adverse effects and therapeutic alternatives.

Conflicts of interest: The authors have none to declare.

\section{References}

1. Neal JM, Bernards CM, Butterworth JF 4th, et al. ASRA practice advisory on local anesthetic systemic toxicity. Reg Anesth Pain Med. 2010;35(2):152-61. doi: 10.1097/AAP.0b013e3181d22fcd

2. El-Boghdadly K, Pawa A, Chin KJ. Local anesthetic systemic toxicity: current perspectives. Local Reg Anesth 2018;11: 35-44. doi: 10.2147/LRA.S154512

3. Verlinde M, Hollmann MW, Stevens MF, Hermanns H, Werdehausen R, Lirk P. Local Anesthetic-Induced Neurotoxicity. Int J Mol Sci. 2016;17(3): 339. Published online 2016 Mar 4. doi:10.3390/ijms17030339

4. Liu SS, Ortolan S, Sandoval MV, et al. Cardiac arrest and seizures caused by local anesthetic systemic toxicity after peripheral nerve blocks: should we still fear the reaper? Reg Anesth Pain Med. 2016;41(1):5-21. doi: 10.1097/AAP.0000000000000329

5. Mörwald EE, Zubizarreta N, Cozowicz C, Poeran J, Memtsoudis SG Incidence of Local Anesthetic Systemic Toxicity in Orthopedic Patients Receiving Peripheral Nerve Blocks. Reg Anesth Pain Med. 2017;42(4):442-5. doi: 10.1097/AAP.0000000000000544.

6. Rubin DS, Matsumoto MM, Weinberg G, Roth S. Local Anesthetic Systemic Toxicity in Total Joint Arthroplasty: Incidence and Risk Factors in the United States From the National Inpatient Sample 1998-2013. Reg Anesth Pain Med. 2018; 43(2):131-7. doi: 10.1097/AAP.0000000000000684

7. Gitman M, Barrington MJ. Local anesthetic systemic toxicity: A review of recent case reports and registries. Reg Anesth Pain Med. 2018;43(2):124-30. doi: 10.1097/AAP.0000000000000721

8. Park H-S, Kim H-J, Ro Y-J, Yang H-S, Koh W-U. Delayed bilateral vocal cord paresis after a continuous interscalene brachial plexus block and endotracheal intubation. A lesson why we should use low concentrated local anesthetics for continuous blocks. Medicine. 2017;96:15(e6598). doi: 10.1097/MD.0000000000006598

9. Nicholas E, Thornton MD. Lidocaine Toxicity During Attempted Epistaxis Cautery. J Emerg Med. 2016;51(3):303-4. doi: 10.1016/j.jemermed.2016.05.034.

10. Nelson M, Reens A, Reda L, Lee D.Profound Prolonged Bradycardia and Hypotension after Interscalene Brachial Plexus Block with Bupivacaine. J Emerg Med. 2018;54(3):e41-e43. doi: 10.1016/j.jemermed.2017.12.004.

11. Bina B, Hersh EV, Hilario M, Alvarez K, McLaughlin B. True Allergy to Amide Local Anesthetics: A Review and Case Pre- sentation. Anesth Prog. 2018;65(2):119-23. doi: 10.2344/ anpr-65-03-06

12. Hayaran N, Sardana R, Nandinie H, Jain A.Unusual presentation of local anesthetic toxicity. J Clin Anesth. 2017;36:36-38. doi: 10.1016/j.jclinane.2016.08.039.

13. Wolfe RC, Spillars A. Local Anesthetic Systemic Toxicity: Reviewing Updates From the American Society of Regional Anesthesia and Pain Medicine Practice Advisory. J PerianesthNurs. 2018;33(6):1000-5. doi: 10.1016/j.jopan.2018.09.005.

14. Neal JM, Salinas FV, Choi DS. Local anesthetic induced myotoxicity after continuous adductor canal block. Reg Anesth Pain Med. 2016;41:723-7. doi: 10.1097/AAP.0000000000000466

15. Hussain N, McCartney CJL, Neal JM, Chippor J, Banfield L, Abdallah FW. Local anaesthetic-induced myotoxicity in regional anaesthesia: a systematic review and empirical analysis. Br J Anaesth. 2018;121(4):822-41. doi: 10.1016/j.bja.2018.05.076.

16. Buchko JZ, Gurney-Dunlop T, Shin JJ. Knee chondrolysis by infusion of bupivacaine with epinephrine through an intra-articular pain pump catheter after arthroscopic ACL reconstruction. Am J Sports Med. 2015;43(2):337-44. doi: 10.1177/0363546514555667.

17. Neal JM, Barrington MJ, Fettiplace MR, et al. The third American Society of Regional Anesthesia and Pain Medicine Practice Advisory on Local Anesthetic Systemic Toxicity. Executive summary 2017. Reg Anesth Pain Med. 2018;43(2):113-23. doi: 10.1097/AAP.0000000000000720.

18. Sekimoto K, Tobe M, Saito S. Local anesthetic toxicity: acute and chronic management [Review]. Acute Med Surg. 2017; 4(2): 152-60. doi: 10.1002/ams2.265

19. Tierney KJ, Murano T, Natal B. Lidocaine-Induced Cardiac Arrest in the Emergency Department: Effectiveness of Lipid Therapy. J Emerg Med. 2016;50(1):47-50. doi:10.1016/j.jemermed.2015.07.035.

20. Lee JE, Kwak K-H. A liver transplant recipient with possible bupivacaine-induced liver injury caused by intraarticular injection after total knee arthroplasty. A case report. Medicine. 2018;97:38(e12481). http://dx.doi.org/10.1097/MD.0000000000012481

21. Tsang TM, Okullo AT, Field J, Mamo P. Lipid rescue for treatment of delayed systemic ropivacaine toxicity from a continuous thoracic paravertebral block. BMJ Case Rep. Published online: 14 Jun 2016. doi:10.1136/bcr-2016-215071

22. Neal JM. Ultrasound-GuidedRegionalAnesthesiaandPatientSafety: UpdateofanEvidence-BasedAnalysis. Reg Anesth Pain Med. 2016;41(2):195-204. doi: 10.1097/AAP.0000000000000295

23. Vasques F, Behr AU, Weinberg G, Ori C, di Gregorio G. A review of local anesthetic systemic toxicity cases since publication of the American Society of Regional Anesthesia Recommendations. Reg Anesth Pain Med. 2015;40(6):698-705. doi: 10.1097/AAP.0000000000000320 
24. Dun-Chi Lin J, Sivanesan E, Horlocker TT, Missair A. Two for One: A Case Report of Intravenous Lipid Emulsion to Treat Local Anesthetic Systemic Toxicity in Term Pregnancy. AA Case Rep. 2017;8(9):235-7. doi: 10.1213/XAA.0000000000000477

25. Neal JM,Hsiung RL, Mulroy MF, Halpern BB,Dragnich AD, Slee AE. ASRA checklist improves trainee performance during a simulated episode of local anesthetic systemic toxicity. Reg Anesth Pain Med. 2012;37(1):8-15. doi: 10.1097/AAP.0b013e31823d825a.

26. Neal JM, Woodward CM, Harrison TK. The American Society of Regional Anesthesia and Pain Medicine (ASRA) checklist for managing local anesthetic systemic toxicity: 2017 Version. Reg Anesth Pain Med. 2018;43:150-3. doi: 10.1097/AAP.0000000000000726

27. Freire V, Bureau NJ. Injectable corticosteroids: take precautions and use caution. Semin Musculoskelet Radiol. 2016;20:401-8. doi: $10.1055 / \mathrm{s}-0036-1594286$.

28. Wernecke C, Braun HJ, Dragoo JL. The Effect of Intra-articular Corticosteroids on Articular Cartilage. A Systematic Review. Orthop J Sports Med. 2015;3(5): 2325967115581163. Published online 2015 Apr 27. doi: 10.1177/2325967115581163

29. MacMahon PJ, Eustace SJ, Kavanagh EC. Injectable corticosteroid and local anesthetic preparations: A review for radiologists. Radiology. 2009;252(3):647-61. doi: 10.1148/radiol.2523081929.
30. Bhatia A, Flamer D, Shah PS, Cohen SP. Transforaminal Epidural Steroid Injections for Treating Lumbosacral Radicular Pain from Herniated Intervertebral Discs: A Systematic Review and Meta-Analysis. Anesth Analg. 2016;122(3):857-70. doi: 10.1213/ANE.0000000000001155.

31. Wong SSC, Qiu Q, Cheung CW. Segmental Spinal Myoclonus Complicating Lumbar Transforaminal Epidural Steroid Injection. Reg Anesth Pain Med. 2018;43(5):554-6. doi: 10.1097/AAP.0000000000000742.

32. Loomba V, Kaveeshvar H, Dwivedi S. Paraplegia After Thoracic Epidural Steroid Injection. A A Case Rep. 2016;7(5): 118-21. doi: 10.1213/XAA.0000000000000402

33. Knezevic NN, Anantamongkol U, Candido KD. Perineural dexamethasone added to local anesthesia for brachial plexus block improves pain but delays block onset and motor blockade recovery. Review. Pain Physician. 2015;18(1):1-14. Available from: https://www.painphysicianjournal.com/site/search?q= Nick+Knezevic. Accessed 28 February 2019.

34. Schairer WW, Nwachukwu BU, Mayman DJ, Lyman S, JerabekSA. Preoperative Hip Injections Increase the Rate of Periprosthetic Infection After Total Hip Arthroplasty. J Arthroplasty. 2016;31(9 Suppl):166-9. doi: $10.1016 /$ j.arth.2016.04.008

Sažetak

\section{LOKALNI ANESTETICI I STEROIDI: KONTRAINDIKACIJE I KOMPLIKACIJE. TRENUTNI KLINIČKI PREGLED}

\section{T. Šimurina, B. Mraoviç, M. Žup̌cić, S. Graf Župčići M. Vulin}

Cilj rada je analizirati učestalost i karakteristike klinički važnijih nusučinaka lokalnih anestetika i kortikosteroida u regionalnoj anesteziji te liječenju akutne i kronične boli temeljem medicinske literature objavljene unatrag pet godina. Pretražene su baze medicinskih podataka na engleskom jeziku pomoću PubMed, Ovid Medline ${ }^{{ }_{1}}$ Google Scholar-a za razdoblje od početka 2015. do kraja 2018. godine. Ovaj narativni pregledni članak donosi pregled komplikacija i kontraindikacija za lokalne anestetike i kortikosteroide s naglaskom na sadašnje stavove u pogledu prevencije, rane dijagnoze i liječenja nuspojava.

Ključne riječi: lokalni anestetici, nuspojave, toksičnost, komplikacije, steroidi, regionalna anestezija i analgezija 